\title{
Lung function in healthy never smoking adults: reference values and lower limits of normal of a Swiss population
}

\author{
O Brändli, Ch Schindler, N Künzli, R Keller, A P Perruchoud, and SAPALDIA* team
}

\begin{abstract}
Background - Reference values and definitions of "normal" are prerequisites for population screening and classification of lung diseases. The aim of this study was to calculate reference values for never smoking Caucasian adults.

Methods - In the SAPALDIA cross sectional study respiratory health was assessed in a random sample of 9651 subjects, aged 18-60 years, from eight areas of Switzerland. Lung function was measured according to ATS criteria including quality control. In 3157 healthy never smoking adults without respiratory symptoms the mean values and fifth percentiles of lung function variables were calculated. For each sex, logarithms of lung function were regressed against age, age squared, and the logarithm of height. Residuals were used to estimate fifth percentiles across the age range using a technique not requiring normality or homoscedasticity of residuals.
\end{abstract}

Results - Most lung function variables were non-linear with age and showed an increase in early adulthood and an accelerated decline thereafter. The reference values for forced vital capacity (FVC) and forced expiratory volume in one second $\left(F E V_{1}\right)$ were higher than those of the European Community for Coal and Steel and those from North America. The prediction equations for lower fifth percentile values defined a stable proportion of subjects outside this limit whereas alternative methods for estimating the fifth percentile showed a loss of sensitivity with age.

Conclusions - The reference equations for mean values of spirometric indices and their lower fifth percentiles gave an improved and unbiased lower limit of normal. The higher mean values may in part be due to the strictly selected population, quality control procedures, cohort effects, and altitude, and are not explained by the statistical model used.

(Thorax 1996;51:277-283)

Keywords: lung function, spirometry, reference values, smoking.

The interpretation of results of lung function tests usually relies on comparison with reference values derived from a "normal" population. The concept of normality may be dealt with differently by clinicians interested in variation due to disease, in surveillance programmes in respiratory, occupational and sports medicine, or in public health screening. In all these circumstances, however, the comparison with normal values may influence decisions which have important implications both on the individual and on the health care system.

Several sets of normal values have been published over the last decades and "normality" for a given age and height may vary considerably across these data. Such variations may be explained by selection criteria of "normal" populations, measurement techniques and devices, biological variability across populations, and statistical modelling. ${ }^{12}$ Furthermore, as for other anthropometric measures such as height, birth cohort effects have been described - that is, mean values within each age group increased over time. For example, Glindmeyer ${ }^{3}$ used normal reference values from 18 cross sectional studies conducted over 130 years to estimate a $55 \mathrm{ml}$ cohort increase per decade among 25 year old men of average height $(173 \mathrm{~cm})$. Based on Dutch data ${ }^{4}$ the cohort effect might be even twice as large. These effects may be explained by the change in the total burden of environmental conditions over time $\mathrm{e}^{5}$ and/or by the technological progress of testing equipment and measurement techniques. Standardisation procedures have been improved $^{6}$ and new equipment, as used in this study, is computer based allowing for ad hoc decisions with regard to acceptability and reproducibility of spirometric manoeuvres. ${ }^{7}$ Given the use of normal values in decision making, cohort effects should be considered a major argument for updating reference values on a regular basis otherwise normal values gradually lose their sensitivity in the detection of abnormal conditions among younger cohorts.

The prediction equations most widely used in Europe are based on different study populations, including smokers, studied in the years 1954 to $1980 .^{89}$ Recent recommendations on equipment and standardisation of procedures propose reference values based on cross sectional studies of lifetime non-smokers. ${ }^{269}$

In this paper we provide results from a recent cross sectional study within a Central European population. ${ }^{10}$ We present reference values based on a well defined selection of the SAPALDIA random population sample. Furthermore, we present fifth percentiles as lower limits of the normal range which account for changes in the distribution of lung function with age. Implications of this approach will be discussed in 
Table 1 Inclusion criteria for study population in the SAPALDIA trial

\begin{tabular}{llll}
\hline & $\begin{array}{l}\text { Men } \\
(n=4743)\end{array}$ & $\begin{array}{l}\text { Women } \\
(n=4908)\end{array}$ & $\begin{array}{l}\text { Total } \\
(n=9651)\end{array}$ \\
\hline $\begin{array}{l}\text { Acceptable and reproducible } \\
\text { pulmonary function tests }\end{array}$ & $4294(90 \cdot 5)$ & $4588(93 \cdot 5)$ & $8882(92 \cdot 0)$ \\
$\begin{array}{l}\text { Health criteria satisfied } \\
\text { Never smokers }\end{array}$ & $3471(73 \cdot 2)$ & $3770(76 \cdot 8)$ & $7241(75 \cdot 0)$ \\
All criteria satisfied & $1693(35 \cdot 7)$ & $2536(51 \cdot 7)$ & $4229(43 \cdot 8)$ \\
\hline
\end{tabular}

Values in parentheses are percentages. at least three and up to eight forced expiratory lung function manoeuvres in order to obtain a minimum of two acceptable and reproducible values. ${ }^{9}$ Each centre was equipped with an identical computerised spirometer (Sensormedics 2200 SP, Bilthoven, The Netherlands) which uses the successfully evaluated and accepted mass flow anemometer technology. The sensor is based on two wires electrically heated to different temperatures and centred in the air stream. The measurement of molecule flow is independent of pressure or temperature. Integrated volumes are BTPS corrected. ${ }^{613}$

Immediate on-screen error codes indicating the major acceptability (including start, duration and end of test) and reproducibility criteria supported the technicians' attempt for standardised procedures. Calibration with a three litre syringe was performed at least once each day.

The three best results for forced vital capacity (FVC), forced expiratory volume in one second $\left(\mathrm{FEV}_{1}\right)$, peak expiratory flow (PEF), expiratory flow at $75 \%, 50 \%, 25 \%$ of FVC $\left(\mathrm{MEF}_{75}\right.$, $\left.\mathrm{MEF}_{50}, \mathrm{MEF}_{25}\right)$, forced mid expiratory flow $\left(\mathrm{MEF}_{25-75}\right)$, forced expiratory time (FET 100), and the five-digit error code for ATS criteria were stored on a hard disk and printed on paper, including flow-volume charts for further documentation. The highest values for FVC and $\mathrm{FEV}_{1}$ of any accepted trial were chosen. Expiratory flow measures were taken from the flow-volume curve with the highest sum of FVC and $\mathrm{FEV}_{1}$.

The height of the participants was measured standing up with their back to the wall and shoes off. The time of day of the examination was also recorded.

Twenty three technicians were hired for the study and underwent two months of full time training before the start of the study. During the study the technicians were supervised by regular visits of an expert of the central team and the locally responsible pneumologist. A quality control study showed no significant differences between individual technicians or teams. ${ }^{14}$

\section{STATISTICAL METHODS}

In a first step we estimated prediction equations for the mean. Equations for the fifth percentiles, which were our primary focus of interest as lower limits of the normal range, were then estimated from the residuals of the models for the mean. In this second step we used the method proposed by Goldstein and Pan ${ }^{1516}$ which does not require any assumptions on the distribution of residuals and thus also works if residuals are not normally distributed and/or if their dispersion varies with age. All regression models were stratified by sex. and (3) spirometric values that did not satisfy the quality criteria for acceptance or reproducibility.

\section{SPIROMETRY}

Spirometric tests were performed in a sitting position with nose clips. Participants performed

\section{Prediction equations for the mean}

To estimate equations for the mean the natural logarithms of lung function variables were regressed against $\ln$ (height), a quadratic function of age, and dummy variables for the study areas, 
Table 2 Mean (SD) characteristics of reference sample

\begin{tabular}{lll}
\hline & $\begin{array}{l}\text { Men } \\
(n=1267)\end{array}$ & $\begin{array}{l}\text { Women } \\
(n=1890)\end{array}$ \\
\hline Height $(\mathrm{cm})$ & $176 \cdot 4(6 \cdot 7)$ & $163 \cdot 5(6 \cdot 5)$ \\
Weight $(\mathrm{kg})$ & $74 \cdot 8(10 \cdot 3)$ & $62 \cdot 0(10 \cdot 6)$ \\
Age (years) & $36 \cdot 8(12 \cdot 1)$ & $41 \cdot 6(12 \cdot 4)$ \\
$<30$ years & $34 \cdot 6 \%$ & $21 \cdot 8 \%$ \\
$30-40$ years & $24 \cdot 4 \%$ & $21.4 \%$ \\
$40-50$ years & $24 \cdot 3 \%$ & $25 \cdot 9 \%$ \\
$>50$ years & $16 \cdot 7 \%$ & $30 \cdot 9 \%$ \\
\hline
\end{tabular}

taking into consideration a random technician effect.

The rationale for considering lung function variables on the logarithmic scale was the assumption that the dependency of average lung function (LF) on height $(\mathrm{H})$ and age $(\mathrm{A})$ is suitably described by a function of the form ${ }^{17} 18$ :

$$
\mathrm{LF}=\mathrm{H}^{\mathrm{c}} \mathrm{f}(\mathrm{A})
$$

Whereas estimating the exponent $\mathrm{c}$ from the untransformed data requires the solution of a non-linear regression problem, the logarithmic transformation of the equation turns the regression problem for $\mathrm{c}$ into a linear one.

The quadratic function in age was originally conceived to consist of two parts, one for the age interval 18-25 years and one for the interval $>25-60$ years. The two quadratic polynomials were treated parametrically in such a way as to agree in $y$ value and slope at the common boundary point of 25 years. The choice of these two intervals was suggested by the ECCS reference equations and corresponds to the
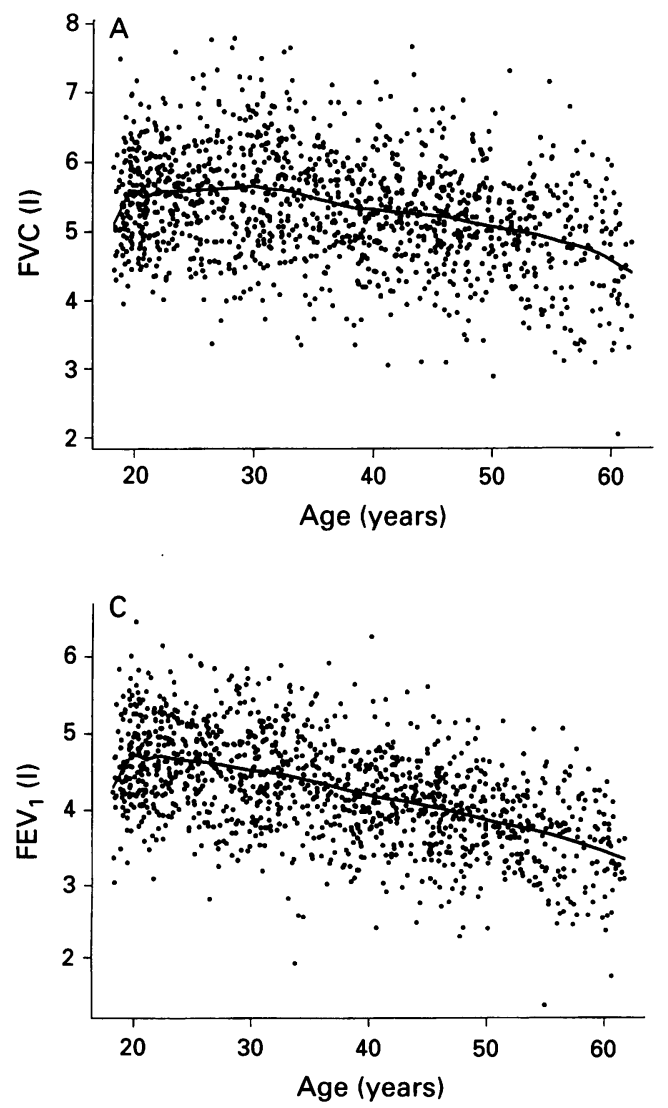

profile of declining pulmonary function over age. ${ }^{819}$ The piecewise quadratic model was only retained if its fit was significantly better than the one of a simple quadratic model defined over the entire interval 18-60 years. If such a simplified model proved to be sufficiently adequate, it was also tested whether or not the quadratic age term was statistically significant.

Individual intercept variables for the study areas - that is, area dummy variables - were introduced in order to guard against potential confounding of the regression estimates due to differences in lung function between study areas unrelated to age and height. To obtain a single intercept term at the end we computed a weighted mean of the area intercepts, choosing weights proportional to the numbers of observations.

\section{Prediction equations for fifth percentiles}

The next step was to compute fifth percentiles in consecutive age groups of residuals each containing 100 observations. These percentiles were then regressed against the age means of the respective groups and their squared values. ${ }^{15}$ Since the percentage of observations defined as being below normal by these percentile equations ought to be close to $5 \%$ in different categories of age and height, we tested the goodness of fit of our equations for the fifth percentiles by comparing the numbers of subnormal observations in the four quartile classes of age and height, respectively, with the cor-
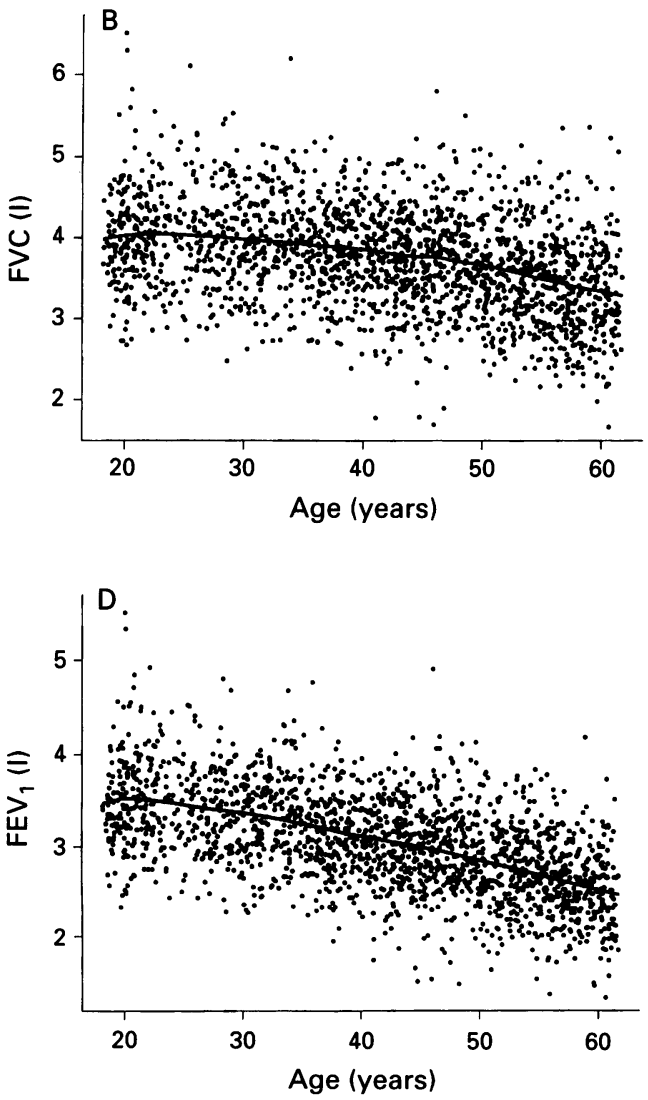

Figure 1 Age dependency of the distribution of FVC in (A) men and (B) women and of FEV, in (C) men and (D) women in the SAPALDIA reference sample. Each subject of the respective sample is represented by a dot. The solid lines represent estimates of the age relationship of mean $F V C$ and $F E V_{1}$, respectively, obtained using the supersmoother
algorithm. 
Table 3 Prediction equations for the means of lung function variables

\begin{tabular}{|c|c|c|c|}
\hline & & $S D^{*}$ & $R^{2} \dagger$ \\
\hline \multicolumn{4}{|l|}{ Men: } \\
\hline FVC (1) & $\begin{array}{l}=\exp \left(-10.321+2.1685 \ln (\mathrm{H})+0.0655 \mathrm{~A}-0.001325 \mathrm{~A}^{2}\right)(\mathrm{A} \leqslant 25) \\
=\exp \left(-9.540+2.1685 \ln (\mathrm{H})+0.0030 \mathrm{~A}-0.000075 \mathrm{~A}^{2}\right)(\mathrm{A}>25)\end{array}$ & $0 \cdot 62$ & $0 \cdot 40$ \\
\hline $\mathrm{FEV}_{1}(1)$ & $\begin{array}{l}=\exp \left(-9.280+1.9095 \ln (\mathrm{H})+0.0795 \mathrm{~A}-0.001698 \mathrm{~A}^{2}\right)(\mathrm{A} \leqslant 25) \\
=\exp \quad\left(-8.240+1.9095 \ln (\mathrm{H})-0.0037 \mathrm{~A}-0.000033 \mathrm{~A}^{2}\right)(\mathrm{A}>25)\end{array}$ & $0 \cdot 51$ & $0 \cdot 44$ \\
\hline PEF $(1 / s)$ & $\begin{array}{l}=\exp \left(-6.189+1.2965 \ln (\mathrm{H})+0.1379 \mathrm{~A}-0.002731 \mathrm{~A}^{2}\right)(\mathrm{A} \leqslant 25) \\
=\exp \left(-4.548+1.2965 \ln (\mathrm{H})+0.0066 \mathrm{~A}-0.000106 \mathrm{~A}^{2}\right)(\mathrm{A}>25)\end{array}$ & $2 \cdot 23$ & 0.05 \\
\hline $\mathrm{MEF}_{25-75}(\mathrm{l} / \mathrm{s})$ & $=\exp \left(-3.205+0.9457 \ln (\mathrm{H})-0.0025 \mathrm{~A}-0.000137 \mathrm{~A}^{2}\right)$ & $1 \cdot 12$ & $0 \cdot 27$ \\
\hline $\mathrm{MEF}_{75}(\mathrm{l} / \mathrm{s})$ & $\begin{array}{l}=\exp \left(-4.440+0.9869 \ln (\mathrm{H})+0.1188 \mathrm{~A}-0.002404 \mathrm{~A}^{2}\right)(\mathrm{A} \leqslant 25) \\
=\exp \left(-2.968+0.9869 \ln (\mathrm{H})+0.0011 \mathrm{~A}-0.000050 \mathrm{~A}^{2}\right)(\mathrm{A}>25)\end{array}$ & 1.91 & 0.03 \\
\hline $\mathrm{MEF}_{50}(1 / \mathrm{s})$ & $=\exp \left(-2.510+0.8156 \ln (\mathrm{H})+0.0012 \mathrm{~A}-0.000119 \mathrm{~A}^{2}\right)$ & $1 \cdot 39$ & $0 \cdot 12$ \\
\hline $\mathrm{MEF}_{25}(1 / \mathrm{s})$ & $=\exp \left(-4.474+1.1258 \ln (\mathrm{H})-0.0165 \mathrm{~A}-0.000120 \mathrm{~A}^{2}\right)$ & 0.73 & 0.42 \\
\hline $\mathrm{FEV}_{1} / \mathrm{FVC}$ & $=\exp \quad(1.526-0.3144 \ln (\mathrm{H})-0.0033 \mathrm{~A})$ & 0.07 & $0 \cdot 18$ \\
\hline \multicolumn{4}{|l|}{ Women: } \\
\hline FVC (1) & $=\exp \left(-9.457+2.0966 \ln (\mathrm{H})+0.0091 \mathrm{~A}-0.000152 \mathrm{~A}^{2}\right)$ & $0 \cdot 50$ & $0 \cdot 38$ \\
\hline $\mathrm{FEV}_{1}(1)$ & $=\exp \left(-8.217+1.8475 \ln (\mathrm{H})+0.0035 \mathrm{~A}-0.000130 \mathrm{~A}^{2}\right)$ & $0 \cdot 41$ & $0 \cdot 47$ \\
\hline PEF $(1 / s)$ & $=\exp \left(-5.790+1.4902 \ln (\mathrm{H})+0.0042 \mathrm{~A}-0.000082 \mathrm{~A}^{2}\right)$ & 1.53 & 0.09 \\
\hline $\mathrm{MEF}_{25-75}(1 / \mathrm{s})$ & $=\exp \left(-3.247+0.9020 \ln (\mathrm{H})+0.0044 \mathrm{~A}-0.000240 \mathrm{~A}^{2}\right)$ & $0 \cdot 81$ & 0.33 \\
\hline $\mathrm{MEF}_{75}(1 / \mathrm{s})$ & $=\exp \left(-4.048+1.1453 \ln (\mathrm{H})+0.0020 \mathrm{~A}-0.000068 \mathrm{~A}^{2}\right)$ & 1.39 & 0.08 \\
\hline $\operatorname{MEF}_{50}(1 / s)$ & $=\exp \left(-2.332+0.7376 \ln (\mathrm{H})+0.0045 \mathrm{~A}-0.000166 \mathrm{~A}^{2}\right)$ & 0.98 & $0 \cdot 17$ \\
\hline $\mathrm{MEF}_{25}(1 / \mathrm{s})$ & $=\exp \left(-4.757+1.1220 \ln (\mathrm{H})-0.0035 \mathrm{~A}-0.000319 \mathrm{~A}^{2}\right)$ & 0.54 & 0.44 \\
\hline $\mathrm{FEV}_{1} / \mathrm{FVC}$ & $=\exp \quad(1.283-0.2640 \ln (\mathrm{H})-0.0037 \mathrm{~A})$ & $0 \cdot 06$ & $0 \cdot 25$ \\
\hline
\end{tabular}

$A=$ age (years); $\mathrm{H}=$ height $(\mathrm{cm}) ; \exp (x)=\mathrm{e}^{x}$.

* Standard deviation of residuals; $\uparrow$ fraction of explained variance.

For instance, for a man of 20 years and $180 \mathrm{~cm}$ the predicted value of $\mathrm{FEV}_{1}$ is computed as follows:
$\mathrm{FEV}_{1}=\mathrm{e}^{(-9 \cdot 280+1.9095 \times \ln (180)+0.0795 \times 20-0.001698 \times 400)}=\mathrm{e}^{1.54}=4.696$

responding expected numbers using $\chi^{2}$ tests of three degrees of freedom. Graphically, the goodness of fit was checked by computing separate logistic regression models for the percentage of subnormal observations with age and $\ln$ (height), respectively, as predictor variables and plotting the corresponding percentage estimates against age and $\ln$ (height), respectively (see fig $2 \mathrm{~A}$ and $2 \mathrm{~B}$ for the goodness of fit with respect to age).

\section{Results}

The study population drawn from a random sample of the Swiss population aged 18-60 years is shown in table 1. Results for each lung function variable refer to participants who performed the tests according to ATS quality criteria.

Demographic data of the 3157 subjects show an overrepresentation of women over 50 years of age (table 2) because women were more likely to have never smoked than men of the same age group.

Figure 1A-D shows the age dependency of the distributions of FVC and $\mathrm{FEV}_{1}$ among men

Table 4 Prediction equations for the fifth percentiles of lung function variables

\begin{tabular}{|c|c|}
\hline \multicolumn{2}{|l|}{ Men: } \\
\hline FVC (1) & $\begin{array}{l}=\exp \left(-10.496+2.1685 \ln (\mathrm{H})+0.0655 \mathrm{~A}-0.001343 \mathrm{~A}^{2}\right)(\mathrm{A} \leqslant 25) \\
=\exp \left(-9.714+2.1685 \ln (\mathrm{H})+0.0030 \mathrm{~A}-0.000093 \mathrm{~A}^{2}\right)(\mathrm{A}>25)\end{array}$ \\
\hline $\mathrm{FEV}_{1}(\mathrm{l})$ & $=\exp \left(-9.281+1.9095 \ln (\mathrm{H})+0.0695 \mathrm{~A}-0.001586 \mathrm{~A}^{2}\right)(\mathrm{A} \leqslant 25)$ \\
\hline PFF (1/s) & $=\exp \left(-8.241+1.9095 \ln (\mathrm{H})-0.0138 \mathrm{~A}+0.000079 \mathrm{~A}^{2}\right)(\mathrm{A}>25)$ \\
\hline PEF (I/S) & $=\exp \left(-4.681+1.2965 \ln (\mathrm{H})-0.0062 \mathrm{~A}+0.000023 \mathrm{~A}^{2}\right)(\mathrm{A}>25)$ \\
\hline $\mathrm{MEF}_{25-75}(\mathrm{l} / \mathrm{s})$ & $=\exp \left(-3.285+0.9457 \ln (\mathrm{H})-0.0195 \mathrm{~A}-0.000003 \mathrm{~A}^{2}\right)$ \\
\hline $\mathrm{MEF}_{75}(\mathrm{l} / \mathrm{s})$ & $\begin{array}{l}=\exp \quad\left(-4.559+0.9869 \ln (\mathrm{H})+0.1048 \mathrm{~A}-0.002272 \mathrm{~A}^{2}\right)(\mathrm{A} \leqslant 25) \\
=\exp \quad\left(-3.087+0.9869 \ln (\mathrm{H})-0.0129 \mathrm{~A}+0.000082 \mathrm{~A}^{2}\right)(\mathrm{A}>25)\end{array}$ \\
\hline $\mathrm{MEF}_{50}(1 / \mathrm{s})$ & $=\exp \left(-2.710+0.8156 \ln (\mathrm{H})-0.0095 \mathrm{~A}-0.000045 \mathrm{~A}^{2}\right)$ \\
\hline $\mathrm{MEF}_{25}(1 / \mathrm{s})$ & $=\exp \left(-4.710+1.1258 \ln (\mathrm{H})-0.0281 \mathrm{~A}-0.000093 \mathrm{~A}^{2}\right)$ \\
\hline FEV $/$ FVC & $(1.393-0.3144 \ln (\mathrm{H})-0.0038 \mathrm{~A})$ \\
\hline Women: & \\
\hline FVC (1) & $=\exp \left(-9.711+2.0966 \ln (\mathrm{H})+0.0111 \mathrm{~A}-0.000191 \mathrm{~A}^{2}\right)$ \\
\hline FEV $_{1}(1)$ & $=\exp \left(-8.398+1.8475 \ln (\mathrm{H})+0.0022 \mathrm{~A}-0.000132 \mathrm{~A}^{2}\right)$ \\
\hline PEF (1/s) & $\left(-5.831+1.4902 \ln (\mathrm{H})-0.0127 \mathrm{~A}+0.000084 \mathrm{~A}^{2}\right)$ \\
\hline $\mathrm{MEF}_{25-75}(1 / \mathrm{s})$ & $\left(-3.431+0.9020 \ln (\mathrm{H})-0.0047 \mathrm{~A}-0.000193 \mathrm{~A}^{2}\right)$ \\
\hline $\mathrm{MEF}_{75}(\mathrm{l} / \mathrm{s})$ & $\left(-4 \cdot 149+1 \cdot 1453 \ln (\mathrm{H})-0.0107 \mathrm{~A}+0.000041 \mathrm{~A}^{2}\right)$ \\
\hline $\mathrm{MEF}_{50}(\mathrm{l} / \mathrm{s})$ & $\left(-2.471+0.7376 \ln (\mathrm{H})-0.0048 \mathrm{~A}-0.000131 \mathrm{~A}^{2}\right)$ \\
\hline $\mathrm{MEF}_{25}(1 / \mathrm{s})$ & $\left(-5 \cdot 120+1 \cdot 1220 \ln (\mathrm{H})-0.0101 \mathrm{~A}-0.000334 \mathrm{~A}^{2}\right)$ \\
\hline & $(1 \cdot 174-0.2640 \ln (\mathrm{H})-0.0042 \mathrm{~A})$ \\
\hline
\end{tabular}

$\mathrm{A}=$ age (years); $\mathrm{H}=$ height $(\mathrm{cm}) ; \exp (x)=\mathrm{e}^{x}$.

For instance, for a man of 40 years and $180 \mathrm{~cm}$ the predicted fifth percentile of FVC is computed as follows:

$F V C=\mathrm{e}^{(-9.714+2.1685 \times \ln (180)+0.003 \times 40-0.000093 \times 1600)}=\mathrm{e}^{1.518}=4.56$ and women of our reference sample. In each of these plots, dots represent individual subjects whereas the solid line represents an estimate of the relationship between average lung function and age. These curves are non-parametric in nature - that is, not based on a parametric model - and were obtained using the supersmoother algorithm. ${ }^{20}$ They all show some degree of curvature, either over the entire age range (women) or in the lower age range (men).

The prediction equations for the mean of the lung function variables are displayed in table 3 as $L F=\exp (a+b \ln$ (height $)+c_{1}$ age $+c_{2}$ age $^{2}$ ), where LF represents any of the lung function variables measured (FVC, $\mathrm{FEV}_{1}, \mathrm{PEF}$, $\mathrm{MEF}_{25-75}, \mathrm{MEF}_{75}, \mathrm{MEF}_{50}, \mathrm{MEF}_{25}$, and $\mathrm{FEV}_{1} /$ FVC) and $\exp (x)$ stands for $\mathrm{e}^{x}$.This equation is equivalent to $\ln (\mathrm{LF})=\mathrm{a}+\mathrm{b} \ln$ (height) $+\mathrm{c}_{1}$ age $+c_{2}$ age ${ }^{2}$. Separate equations for men younger than 25 years for FVC, $\mathrm{FEV}_{1}, \mathrm{PEF}$, and $\mathrm{MEF}_{75}$, respectively, fitted our data significantly better than a single equation. A linear polynomial in age was found adequately to describe the age dependency of $\ln \left(\mathrm{FEV}_{1} / \mathrm{FVC}\right)$. For all other lung function variables (except $\mathrm{MEF}_{25}$ in women) the quadratic age term was statistically significant.

The equations for the fifth percentiles, which we recommend as a lower limit of the normal range, are displayed in table 4 and are of the same form as those for the mean. In fig 2 the equations for the fifth percentiles of $\mathrm{FEV}_{1}$ in men and women are graphically validated. A comparison with the European Community for Coal and Steel (ECCS), ${ }^{9}$ earlier Swiss values, ${ }^{21}$ and more recent North American reference values ${ }^{2223}$ is shown in figs $3 \mathrm{~A}-\mathrm{D}$ for the mean of FVC and FEV 1 in relation to age.

\section{Discussion}

The reference values for FVC and $\mathrm{FEV}_{1}$ obtained from healthy never smoking adults aged 18-60 years participating in our cross sectional epidemiological study are higher than those obtained from other published equations. ${ }^{921-23}$ The relevance of higher reference values is best 

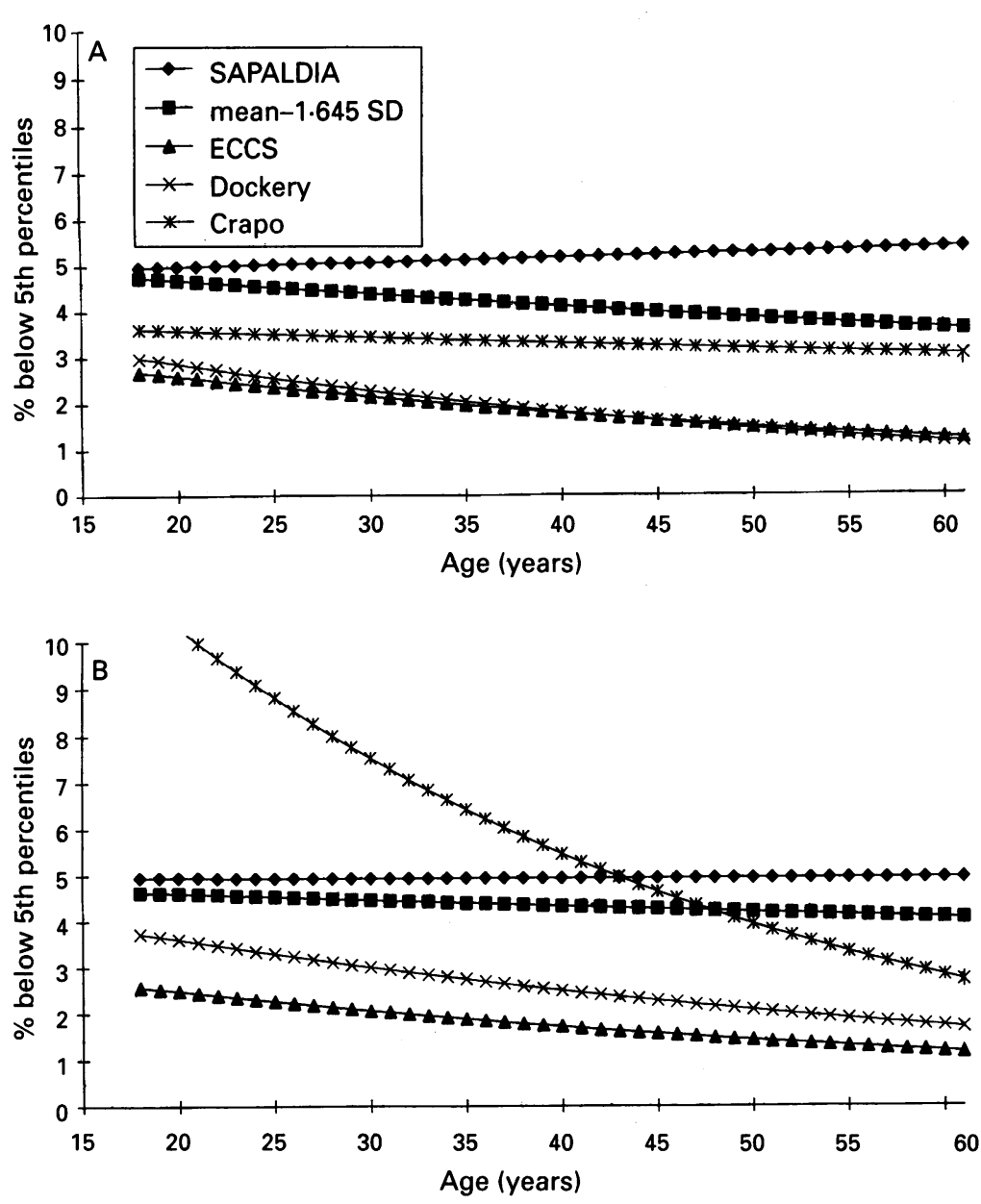

Figure 2 SAPALDIA fifth percentiles for FEV (according to the prediction equations of table 4) are more accurate than traditional percentile estimates. They define a stable percentage of subnormal subjects in the reference population. In contrast, percentages of subnormal subjects in the reference population defined by the fifth percentiles according to the ECCS, Dockery, and Crapo decrease with age, indicating a loss of sensitivity. $A=$ male reference population; $B=$ female reference population.
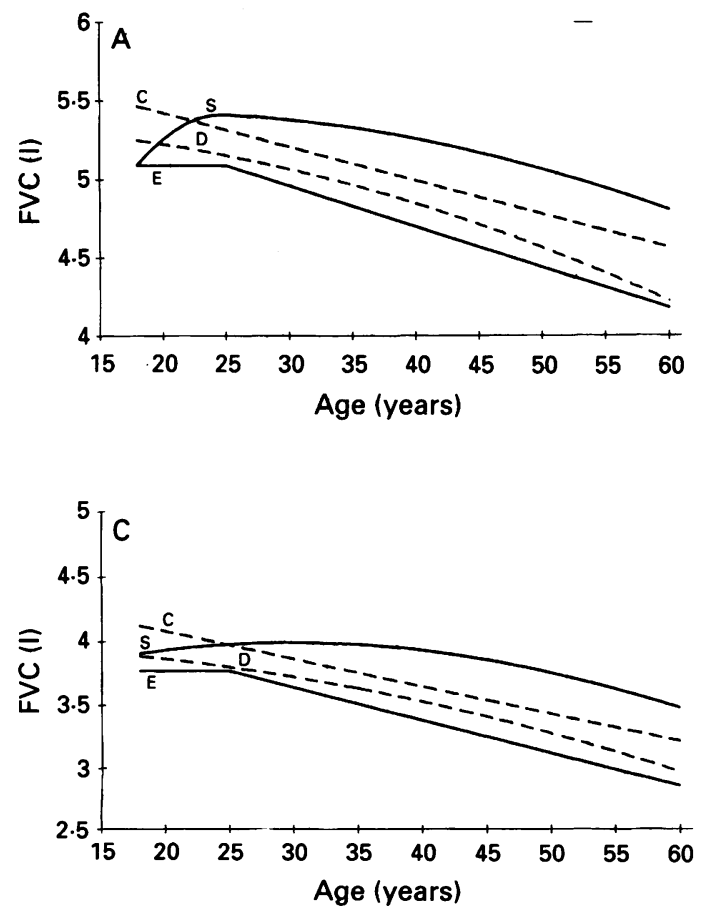

Figure 3 Age dependency of mean values of (A) FVC and (B) $F E V_{1}$ in men $(175 \mathrm{~cm}$ ) and (C) FVC and (D) FEV in women $(165 \mathrm{~cm})$ in comparison with published reference values. $E=E C C S(1983$, summary equations, established with different equipment up to three decades ago by graphical comparison of data in the literature); $D=D o c k e r y$ et al (1985, 2551 participants of the US six city study tested 1974-7 with water seal spirometers); $A=A$ mrein et al ${ }^{21}$ (1969, occupation-based sample of 1200 subjects from Basel including smokers, tested with a pneumotachograph, only $F E V D$; and $C=$ Crapo et al ${ }^{22}$ (1981, 251 never smoking mormons tested at $1400 \mathrm{~m}$ above sea level with a water-sealed spirometer in 1980).

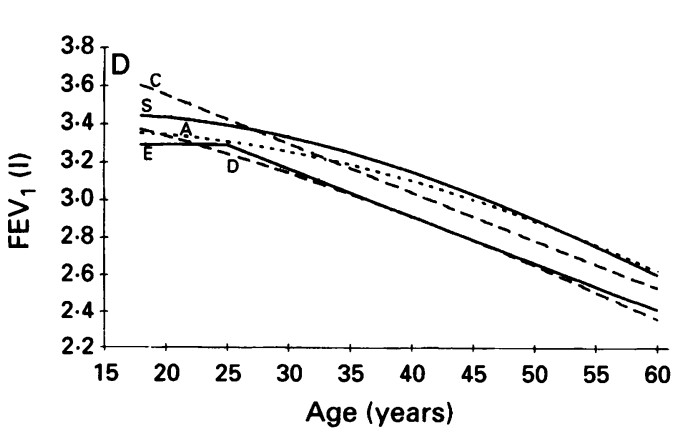

demonstrated at the estimated lower limit of normal. SAPALDIA fifth percentiles classify a larger percentage of our reference population as abnormal than other published reference equations (fig $2 \mathrm{~A}$ and $\mathrm{B}$ ). This clinically relevant difference may have different causes including differences in the populations, technical factors, altitude, or cohort effects. As far as percentile estimates are concerned, statistical modelling may partly explain the differences (see later).

The observed differences compared with other reference values, especially the ECCS, ${ }^{9}$ may be due to stricter selection criteria for our reference population, which only included asymptomatic never smokers.

The exclusion of smokers and ex-smokers is justified by epidemiological and clinical experience which has shown an accelerated decline of lung function in smokers. ${ }^{24}$ Women were overrepresented, particularly in the higher age groups, because they were more likely never to have smoked than men.

Reference values are given for never smokers without respiratory symptoms (table 2). Exclusions were based on the questionnaire results only. No clinical or chest radiographic examinations were performed. This might result in the inclusion of some patients with asymptomatic lung disease of the restrictive type. The potential bias toward lower values and increased variability in higher age groups should be regarded as negligible given the low prevalence of restrictive lung disease among asymptomatic adults. participation rate of $59 \%$ in the SAPALDIA

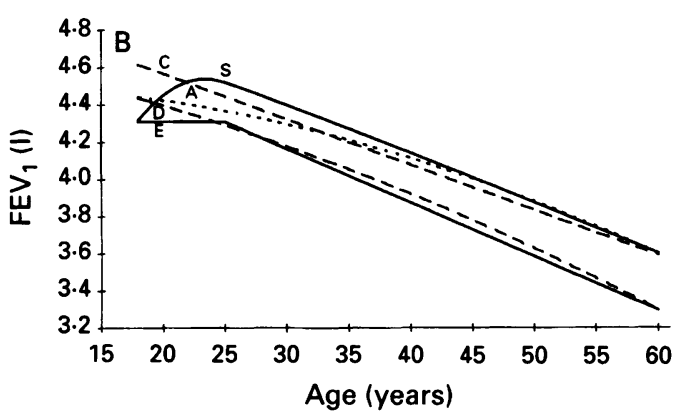

\section{STUDY POPULATION}

A potential selection bias can be seen in the 
study. A separate analysis of non-participants was conducted in one SAPALDIA area and showed an overrepresentation of subjects of lower social class and lower educational level and a lower prevalence of symptoms of wheezing in the non-participants. ${ }^{12}$ Given our selection of asymptomatic subjects, this participation pattern might bias lung function toward higher values.

\section{TECHNICAL FACTORS}

Equipment has changed since the years 1954 to 1980 when the lung function tests in the other reference populations were performed. On-line feedback about acceptability of spirometric performance was not available decades ago. We argue that immediate feedback tends to yield higher values in measures that depend on cooperation of the subject - for example, on-screen information about the ATS end of test criteria gives a direct incentive for the technicians to achieve full expiration. Repetitive maximal performance is enhanced by an on-line check of reproducibility. Strict fulfillment of the manoeuvre for start criteria for example, back extrapolation of less than $5 \%$ or less than $100 \mathrm{ml}$ of FVC - is readily checked by computer devices and thus likely to optimise $\mathrm{FEV}_{1}$. Based on these arguments one would expect attenuated differences for flow measures that are independent of effort. In fact, the most striking difference in our reference values compared with those of the

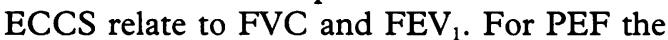
differences were much smaller, further supporting our argument for the importance of on-line quality criteria. No quality criteria have been defined for PEF by the ATS ${ }^{2}$ and no such criteria were used in our software. The lack of such criteria must be considered as a major reason for the increased variability in $\mathrm{PEF}$ measurements.

We used a computerised open spirometer with a mass flow sensor based on a hot wire system which fullfilled ATS performance criteria. ${ }^{6}$ Strictly standardised technique, regular supervision, and separate spirometric quality control studies were used to minimise variability between devices, teams, and technicians. ${ }^{14}$ These quality controls, based on repetitive measurements on volunteers, showed no systematic differences between the 23 technicians or the eight teams. To confirm the validity of the hot wire open systems a closed system (water-sealed spirometer, Sensormedics 2400) was included in our spirometer comparison test ${ }^{14}$ and the results obtained with the two different systems were in good agreement. Thus, our use of a mass flow sensor does not explain the observed higher values.

It might be argued that choosing the best values for FVC and $F E V_{1}$ from different curves according to ATS criteria tends to provide higher values. Wise $e t a l^{25}$ found that the largest single value from all manoeuvres showed the least short term variability for both $\mathrm{FEV}_{1}$ and FVC and concluded that there is no reason to change the currently recommended ATS selection method.

\section{ALTITUDE}

The potential effect of altitude $(83 \%$ of the participants lived $200-1200 \mathrm{~m}$ above sea level and none lived above $1600 \mathrm{~m}$ ) was not tested separately. Theoretically, and based on measurements on healthy African adults, altitude can have a variable effect of up to $263 \mathrm{ml} /$ $1000 \mathrm{~m}$ on FVC in men. ${ }^{2627}$ Statistical analysis of our data would support a small bias toward higher values at altitude which might have influenced our results for FVC and $\mathrm{FEV}_{1}$ by $0.5 \%$ in men and $1 \%$ in women at most. This bias might be slightly larger (up to $1 \cdot 1 \%$ in men and $1.6 \%$ in women) for the flow parameters. However, these differences are small compared with those between our predicted values and previously established reference values.

\section{STATISTICAL MODEL}

When lung function variables are considered on the logarithmic scale their age dependency showed a significant amount of curvature in the interval 18-60 years with one exception (Tiffeneau) which required a quadratic age term in all these models. For FVC, $\mathrm{FEV}_{1}$, $\mathrm{PEF}$, and $\mathrm{MEF}_{75}$ in men a piecewise quadratic function in age with a break point at 25 years provided a significant improvement of fit over a simple quadratic function defined over the entire interval. The non-linearity of the logarithmic transformation implies that a linear relationship between untransformed data is no longer linear after data have been logarithmised. This leads to the seemingly paradoxical situation that, to model a linear relationship between untransformed lung function data and age, a quadratic polynomial in age is necessary in the logarithmic representation of lung function values.

Our rationale for modelling lung function variables on the logarithmic scale has been outlined in the method section. Since the use of the logarithmic transformation in this context has been debated, we decided also to compute a variant of Cole's proportional model for FVC and FEV ${ }_{1}{ }^{17}$ This model was of the form:

$$
\mathrm{LF}=\text { height }^{\mathrm{c}}\left(\mathrm{b}_{0}+\mathrm{b}_{1} \text { age }+\mathrm{b}_{2} \text { age }^{2}\right) .
$$

Reference curves for the mean obtained from this model were almost identical to those obtained from our model, which shows that the particular choice of the scale on which the lung function variables are considered has only a minor impact on the final results.

\section{COHORT EFFECTS}

Our higher reference values are in part also explained by cohort effects. Lung function depends on a variety of individual, behavioural, and environmental factors. If the lifetime profile of all these factors changes over decades, cross sectional lung function might increase by up to $5 \mathrm{ml} /$ year for FVC and $\mathrm{FEV}_{1} \cdot{ }^{3}$ Our subjects studied in 1991 probably experienced different lifetime exposures in terms of nutrition, exercise, air quality, occupational hazards, and environmental tobacco smoke than earlier ref- 
erence populations. We assume that the level of all these factors has changed in the population resulting in higher lung function values than 2-3 decades ago. It is likely that changes in height only partly explain the observed changes in lung function. It will be of interest to see whether the results of the European Community Respiratory Health Survey ${ }^{11}$ will confirm this pattern.

\section{WHAT IS THE LOWER LIMIT OF NORMAL}

Because our lung function data showed changes in variability with age and some indication of non-normality of the distribution of residuals, we decided to derive direct estimates of the fifth percentiles. This approach provides more accurate estimates than the traditional one assuming a constant difference $(1.645$ standard deviations) between the mean and fifth percentiles (fig 2). ${ }^{18}$

It must be emphasised that cutoff points defined for "normal" by other widely used reference values lose sensitivity with increasing age within our reference sample - for example, in fig 2 the most extreme case is given for $\mathrm{FEV}_{1}$ among women based on Crapo's reference values; older women of our reference population are far less likely to be defined as "below normal" than younger ones. In other cases the discrepancies are less pronounced but follow the same pattern. We strongly recommend a concept for "lower limits of normal" with a stable alpha error - that is, the probability of declaring a healthy person as being "below normal" should be independent of age. Normal values published so far have apparently given less priority to this goal.

If the SAPALDIA lower limits of normal were used instead of those of the ECCS up to three times as many subjects of our reference population would be considered abnormal for FVC and $\mathrm{FEV}_{1}$. This has direct implications in the definition of disease and disease incidence, and may influence indirectly the cost of medical care as well as disability compensation. Sensitivity and specificity of widely used reference values should be tested.

\section{LIMITATIONS AND USEFULNESS}

Our reference values should only be used for the age group studied (18-60 years). Extensions beyond these age limits are not warranted. The reference values are "optimal" rather than "normal" and pertain to healthy subjects who have never smoked. They are of particular use in screening healthy subjects and in detecting early changes in lung function due to smoking or other environmental agents.

Despite these caveats we suggest the use of our reference values in comparable European populations.

The authors wish to thank the SAPALDIA field workers as well as the authorities of the participating cantons (Aargau, Basel, Genève, Graubünden, Tessin, Waadt, Wallis, Zürich) for their logistic and financial support.

The members of the SAPALDIA team are as follows: Study director: Ph Leuenberger (p), Program director: U AckermannLiebrich (e), P Alean (am), K Blaser (a), G Bolognini (p), J P Bongard (p), O Brändli (p), P Braun (p), C Bron (1), M Brutsche (l), C Defila (m), G Domenighetti (p), S Elsasser (l),
L Grize (s), P Guldimann (l), P Hufschmid (1), W Karrer (p), H Keller-Wossidlo (o), R Keller (p), N Künzli (e), J C Luthy (1), B W Martin (e), T Medici (p), Ch Monn (am), A G Peeter (pa), A P Perruchoud (p), A Radaelli (l), Ch Schindler (s), J Schwartz (s), G Solari (p), M Schöni (p), J M Tschopp (p), B Villiger (p), B Wüthrich (a), J P Zellweger (p), E Zemp (p) Villger (p), B Wüthrich (a), J P Zellweger (p), E Zemp (e) (a), allergology; (o), occupational medicine; (am), air pollution monitoring; (p), pneumology; (e), epidemiology; (pa), palynology; (1), local assistant (MD); (s), statistics; (m), meteorology. SAPALDIA is part of the Swiss National Research Program 26A supported by the Swiss National Science Foundation (gran No. 4026-28099) and by the Federal Office of Education and Science. SAPALDIA Basel is part of the European Respiratory Health Survey.

1 Becklake MR. Concepts of normality applied to the measurement of lung function. Am f Med 1986;80:1158 64.

2 American Thoracic Society. Lung function testing: selection of reference values and interpretative strategies. $A m$ Rev Respir Dis 1991:144:1202-18.

3 Glindmeyer HW, Diem JE, Jones RN, Weill H. Noncomparability of longitudinally and cross sectionally determined annual change in spirometry. Am Rev Respir Dis 1982;125:544-8

4 Xu X, Larid N, Dockery DW, Schouten JP, Rijcken B, Weiss ST. Age, period, and cohort effects on pulmonary function in a 24-year longitudinal study. $A m \mathcal{f}$ Epidemiol 1995;141:554-65.

5 Vollmer WM. Reconciling cross sectional with longitudinal observations on annual decline. Occup Med 1993;8:33951.

6 American Thoracic Society. Standardization of spirometry 1987 update. Am Rev Respir Dis 1987;136:1285-98.

7 Hankinson JL. Instrumentation for spirometry. Occup Med 1993;8:397-407.

8 Quanjer PhH (ed). Standardized lung function testing. Bull Eur Physiopathol Respir 1983;19(Suppl 5):1-95.

9 Quanjer PhH, Tammeling GJ, Cotes JE, Pedersen OF, Peslin $R$, Yernault JC. Lung volumes and forced ventilatory flows. Eur Respir f 1993;6(Suppl 16):5-40.

10 Ackermann-Liebrich U and SAPALDIA team. Schweizer Studie "Luftverschmutzug und Atemwegserkrankungen bei Erwachsenen - SAPALDIA". Atemwegs-Lungenkrankheiten 1993;5:190-4.

11 Burney PGY, Luczynska C, Chinn S, Jarvis D. The European Community respiratory health survey. Eur Respir $\mathcal{F}$ 1994;7:954-60.

12 Luethi JC. Etude du biais dû aux non-repondants dans une étude épidemiologique (SAPALDIA). Inaugural thesis, Medical Faculty, University of Lausanne, Switzerland 1993.

13 Nelson ST, Gardner RM, Crapo RO, Jensen RL. Performance evaluation of contemporary spirometers. Chest 1990;97:288-96.

14 Künzli N, Ackermann-Liebrich U, Keller R, Perruchoud AP, Schindler Ch and SAPALDIA team. Variability of FVC and FEV due to technician, team, device and subject in an eight center study: three quality control studies in SAPALDIA. Eur Respir f 1995;8:371-6.

15 Goldstein $\mathrm{H}$, Pan $\mathrm{H}$. Percentile smoothing using piecewise polynomials with covariates. Biometrics 1992;48:1057-68.

16 Schindler C, Brändli $O$ and SAPALDIA team. Modelling percentiles of lung function variables. Proceedings of the 9th International Workshop on Statistical Modelling, Exeter, 1994.

17 Cole TJ. Linear and proportional regression models in the prediction of ventilatory function. $\mathcal{F} R$ Statist Soc $A 1975$; 138:297-324.

18 Dockery DW. Percentile curves for evaluation of repeated measures of lung function. Occup Med 1993;8:323-38.

19 Robbins DR, Enright PL, Sherrill DL. Lung function development in young adults: is there a plateau phase? Eur vespir 7 1995;8:768-72.

20 Hastie TJ, Tibshirani RJ. Generalized additive models, monographs on statistics and applied probability 43. London: Chapman and Hall, 1990.

21 Amrein R, Keller R, Joos H, Herzog H. Neue Normalwerte für die Lungenfunktionsprüfung mit der Ganzkörperplethysmographie. Dtsch Med Wschr 1969;94:1785-93.

22 Crapo RO, Morris AH, Gardner RM. Reference spirometric values using techniques and equipment that meet ATS recommendations. Am Rev Respir Dis 1981;123:659-64.

23 Dockery DW, Ware, JH, Ferris Jr. BG, Glicksberg DS, Fay ME, Avron S III, et al. Distribution of forced expiratory volume in one second and forced vital capacity in healthy, volume in one second and forced vital capacity in healthy, white, adult never-smo

24 Dockery DW, Speizer FE, Ferris Jr BG, Ware JH, Louis TA, Spiro III A. Cumulative and reversible effects of lifetime smoking on simple tests of lung function in adults. Am Rev Respir Dis 1988;137:286-92.

25 Wise RA, Connett J, Kurnow K, Grill J, Johnson L, Kannar $\mathrm{R}$, et al. Selection of spirometric measurements in a clinical trial: the Lung Health Study. Am $¥$ Respir Crit Care Med 1995;151:675-81.

26 Heath D, Williams DR. The lung at high altitude. Invest Cell Pathol 1979;2:147-56.

27 White NW, Hanley JH, Lalloo UG, Becklake MR, et al. Review and analysis of variation between spirometric values reported in 29 studies of healthy African adults. $\mathrm{Am}$ ues reported in 29 studies of healthy Africa
$\mathcal{7}$ Respir Crit Care Med 1994;150:348-55.

28 Statistical Sciences. S-PLUS for Windows Version 3.2 Supplement. Seattle: StatSci, 1994. 